\title{
Repair Ruptur Tendon Achiles Neglected dengan Teknik Lindholm Modifikasi
}

\author{
Dafit Firmansyah¹, Rizki Rahmadian², Hermansyah²
}

\begin{abstract}
Abstrak
Ruptur neglected tendon Achilles seringkali muncul dengan defek yang besar sehingga membutuhkan teknik rekonstruksi khusus. Beberapa teknik operasi telah dideskripsikan dalam literatur. Penulis menampilkan suatu kasus yang mengunakan prosedur Modifikasi Lindholm. Laporan kasus, seorang pasien wanita 34 tahun yang datang ke trauma center dengan keluhan nyeri dan kelemahan yang menetap di pergelangan kaki kiri. Terdapat perubahan kontur kaki di posterior dengan celah yang dapat diraba pada pemeriksaan fisik. Pada pasien ini dilakukan operasi repair tendon Achiles teknik modifikasi Lindholm. Pasca bedah dan rehabilitasi, pasien dapat melakukan plantarflexy maksimal dan dapat melakukan single limb heel rise pada sisi yang sakit. Banyak teknik yang dapat dilakukan dalam rekonstruksi ruptur neglected tendon achilles. Tidak ada data konkret untuk mendukung satu teknik lebih baik dari yang lain, karenanya tidak ada "gold standard". Kemampuan pasien untuk melakukan single limb heel rise pada sisi yang sakit, menjadi indikasi tindakan yang berhasil.
\end{abstract}

Kata kunci: Ruptur achiles, Teknik Lindholm

\begin{abstract}
Neglected achilles tendon ruptur often present a large defect, that require special reconstructive techniques. Multiple surgical techniques have been described in the literature. The authors present a case using Modified Lindhlom procedure. Case report, a 34-years-old female patient who come to the trauma center with persistent pain and weakness at the left ankle. We can see a change in contour of the posterior leg with palpable gap on physical examination. In this patient we applied Modified Lindholm technique. The result post surgical treatment and rehabilitation, patient can do maximal plantarflexy and achieve a single limb heel rise on the affected side. Many surgical treatments are available for reconstruction of a neglected achilles tendon rupture. There is no concrete data to support one technique over another; hence, there is no "gold standard". The ability of the patient to achieve a single limb heel rise on the affected side, most often indicates a successful outcome.
\end{abstract}

Keywords : Achilles rupture, Lindholm technique

Affiliasi penulis : 1. Pendidikan Dokter Spesialis Bedah FK Unand (Fakultas Kedokteran Universitas Andalas), 2. Bagian Bedah Divisi Orthopedi RSUP Dr. M. Djamil, Padang.

Korespondensi : Dafit Firmansyah e-mail: drdafit@yahoo.com

\section{PENDAHULUAN}

Frekuensi sebenarnya ruptur tendon achilles belum diketahui, tetapi secara historis cedera ini dianggap kejadian langka yang terjadi kurang dari $0,2 \%$ dari populasi dan terus meningkat dalam decade terakhir. Saat ini ruptur tendon Achilles adalah ruptur tendon paling umum terjadi pada ekstremitas bawah dan penyebab $40 \%$ dari seluruh keajadian kerusakan tendon. Pasien dengan ruptur tendon Achilles tidak mampu berdiri pada ibu jari kaki dari sisi yang sakit, namun gerakan plantar fleksi tetap dapat dilakukan terutama bila ruptur yang terjadi parsial. Nyeri ringan dan tidak adanya gangguan gerakan plantar fleksi yang terlihat jelas dapat menyebabkan misdiagnosis diawal kejadian pada $20-25 \%$ kasus. Kegagalan untuk menegakkan diagnosis sejak awal adalah alasan yang paling umum yang mengakibatkan penundaan pengobatan. ${ }^{1,2}$

Ada banyak terminologi yang digunakan untuk mendeskripsikan kondisi neglected atau ruptur kronis. Tidak ada konsensus mengenai waktu spesifik di mana ruptur akut menjadi ruptur neglected, meskipun banyak ahli menganggap 4 minggu merupakan interval yang sesuai. Terlepas dari kurangnya definisi secara kronologis, ruptur tendon neglected ditandai dengan sulitnya mencapai aposisi end-to-end dari ujung-ujung tendon dengan posisi kaki plantarfleksi selama rekonstruksi bedah. ${ }^{1,2,3}$

Ruptur neglected dapat sembuh tanpa operasi karena terbentuknya jaringan parut di celah ruptur. Namun, karena terjadinya kontraktur kompleks otot trisep surae, panjang fungsional dari unit otot-tendon dapat menjadi lebih panjang. Hal ini menyebabkan berkurangnya kekuatan plantarfleksi, stabilitas pergelangan kaki berkurang dan terganggunya pola/gaya berjalan..$^{2.3}$

\section{Evaluasi Klinis}

Terabanyak gap di lokasi ruptur pada palpasi jarang ditemukan pada pemeriksaan fisik karena adanya jaringan parut. Namun, dengan palpasi yang hati-hati atau inspeksi visual secara langsung, lokasi dari daerah yang ruptur neglected dapat dibedakan karena adanya perubahan konsistensi dari jaringan dan kontur bagian posterior kaki. Temuan tambahan dari pemeriksaan klinis akan bergantung pada panjang fungsional dari tendon yang mengalami penyembuhan

Pada pasien akan ditemukan kekuatan dorsofleksi dan penurunan kekuatan plantarfleksi dibandingkan 
dengan tungkai kontralateral. Pasien sering mengeluhkan mudah mengalami kelelahan bila berolahraga dan tidak bisa berdiri dengan ujung kaki (tumit ditinggikan). Selama berjalan terdapat perlambatan heel-off dan langkah yang pendek.

Tes Thompson, dilakukan dengan posisi pasien pronasi dengan kedua kaki diletakkan di bagian ujung meja pemeriksaan. Betis pasien diremas, dan apabila tendon achiles intak, maka kaki akan bergerak dengan gerakan plantarfleksi. Hal ini disebabkan karena tendon achiles menghubungkan kompleks otot gastrocnemius soleus ke kalkaneus. Ketika terdapat robekan pada tendon, sehingga tendon tidak lagi menghubungkan kompleks otot gastrocnemius soleus dengan calcaneus, maka tidak akan ditemukan gerakan plantarfleksi yang cukup kuat seperti yang terjadi pada kaki yang sehat. 2,3,4

Tes Matles juga dilakukan dengan posisi pasien pronasi, lutut fleksi $90^{\circ}$ pada ankle yang tendon achilesnya ruptur, maka posisinya akan lebih dorsofleksi dibanding sisi yang normal. Hal ini karena tidak ada tegangan tendon yang menghubungkan kompleks otot gastrocnemius soleus dengan kalkaneus, sehingga efek gravitasi membuat kaki lebih dorsofleksi pada bagian yang cedera. Copeland menjelaskan sebuah tes yang dilakukan dengan sphygmomanometer. Manset sphygmomamometer di pasang melingkar di tengah betis pada pasien yang berbaring pronasi. Manset di pompa hingga $100 \mathrm{mmHg}$ dengan kaki plantar fleksi. Kaki didorsofleksikan oleh pemeriksa. Jika tekanan meningkat hingga $140 \mathrm{mmHg}$, unit muskulotendinious dapat diperkirakan intak. Jika dua dari tes di atas positif, maka diagnosis dari ruptur tendon achiles dapat ditegakkan. 5,6,7

\section{Pencitraan}

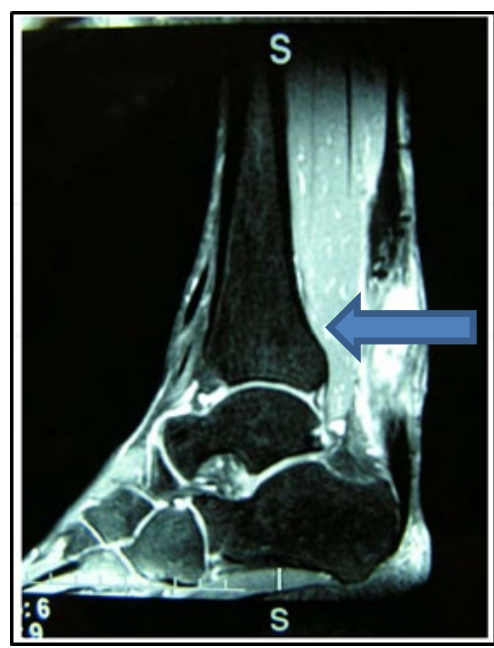

Gambar 1. Magnetic Resonance Imaging. Tampak defek ruptur tendon achiles neglected yang telah disi jaringan parut

Magnetic Resonance Imaging (MRI) dapat menunjukkan secara detail kondisi ujung-ujung tendon yang ruptur. MRI adalah alat yang bermanfaat untuk mengkonfirmasi diagnosis klinis, dan lebih penting lagi untuk menilai jumlah defek fungsional pada tendon Achilles untuk perencanaan pre operasi. ${ }^{1,2}$

\section{Tatalaksana}

Rekonstruksi bedah dinilai paling tepat untuk mengembalikan fungsi tendon sebaik mungkin, tetapi tatalaksana non-bedah lebih dianjurkan untuk pasien dengan kondisi kulit yang buruk, riwayat merokok, komplikasi jaringan lunak akibat dari operasi sebelumnya, dan diabetes mellitus menahun. ${ }^{1,4}$

Banyak teknik bedah untuk tatalaksana ruptur achiles neglected. Tujuan utama dari setiap tindakan bedah adalah untuk mengembalikan fungsi dan kekuatan dari otot kompleks gastrocnemeussoleus dengan menyusun ulang hubungan length-tension yang optimal. Repair end-to-end menjadi ideal jika celah antara ujung-ujung tendon memungkinkan aposisi langsung setelah reseksi dari jaringan parut. Tindakan ini akan mengembalikan kekuatan isokinetik achilles yang maksimal karena dengan cara inilah panjang tendon saat sebelum cedera dapat dicapai. . $^{5,8}$

Secara umum telah dipahami bahwa, gap sebesar 1-2 cm masih memungkinkan untuk dilakukan repair end-to-end. Namun, perbaikan primer merupakan penatalaksanaan yang jarang dilakukan untuk ruptur yang kronis karena adanya kemungkinan terjadi pemendekan dan kontraktur dari unit tendon-otot gastrocnemius-soleus. ${ }^{1,2,3}$

Berbagai teknik gastrocnemeus-soleus fascia turndown telah dijelaskan. Salah satu diantaranya adalah Lindholm technique. Pada posisi pronasi, lakukan sayatan kurvalinear di bagian posterior yang memanjang dari midcalf ke calcaneus. Sayat deep fascia di midline hingga ruptur tendon terekspos. Lakukan debridement pada ujung tendon dan aproksimasi ujung-ujung tendon tersebut dengan jahitan matrass menggunakan benang atau wire. Bentuk dua flap dari bagian proximal tendon dan aponeurosis gastrocnemius, masing-masing dengan ukuran lebar $1 \mathrm{~cm}$ dan panjang 7-8cm. Batas distal flap sekitar $3 \mathrm{~cm}$ proksimal dari area ruptur. Putar masingmasing flap $180^{\circ}$ melalui stump distal achiles yang telah diberi lubang sehingga bagian permukaan luar flap terletak di jaringan subkutan distal. Jahitkan tiap-tiap flap ke bagian distal dari tendon sehingga daerah ruptur tertutup dengan baik. Agar lebih kuat, ditambahkan graft dari tendon plantaris dengan teknik figure of eight dari posterior ke anterior melalui ujung-ujung tendon yang ruptur.. Tutup luka dan hati-hati pada saat penenempatan tendon sheath menutupi area rupture. ${ }^{5,7,8}$

\section{Komplikasi}

Meskipun hampir keseluruhan operasi menghasilkan outcome yang baik dan fungsional, namun komplikasi yang signifikan masih tetap dapat terjadi. Salah satu variabel dalam operasi rekonstruksi adalah menentukan tegangan yang optimal pada tendon yang diperbaiki. Jika kompleks tendon terlalu tegang, maka pasien akan mengalami kesulitan dalam 
berjalan, jika terlalu longgar kekutan tendon achiles tidak adekuat. $^{4}$

Penentu utama dari hasil yang baik adalah kemampuan pasien untuk berdiri dengan mengangkat tumit pada satu tungkai yang cidera. Pada kebanyakan kasus, kondisi ini dapat dicapai sekitar 6 bulan pasca operasi, tetapi hasil ini tidak mungkin didapatkan jika rekonstruksi menghasilkan kondisi tendon yang terlalu lentur atau tidak cukup tegang. ${ }^{1,2}$

\section{LAPORAN KASUS}

Pasien perempuan, 34 tahun datang ke poli orthopedi RSUP M Djamil dengan nyeri persisten dan kelemahan pergelangan kaki kiri. Dia menjelaskan 4 bulan sebelum gejala ini muncul, pergelangan kaki kiri terkena pecahan kaca. Pasien ditangani di IGD rumah sakit daerah, dilakukan penjahitan luka. Sejak luka sembuh hingga sekarang pasien kesulitan berjalan terutama naik dan turun tangga.

Keadaan umum dan vital sign dalam batas normal, visual analog score (VAS) 4. Mata konjungtiva tidak anemis, thoraks dan abdomen dalam batas normal. Status lokalis regio pedis sinistra, pada inspeksi tidak ada luka, tampak perubahan kontur tungkai di posterior bagian distal cruris. Teraba gap, tes Thomson (+), Tes Matles (+). Hasil laboratorium dalam batas normal.

Pasien didiagnosis dengan ruptur tendon achilles sinistra neglected. Pada pasien dilakukan repair dengan teknik Lindholm Modifikasi dan graft tendon plantaris. Setelah pembedahan, tungkai difiksasi dengan plaster casting (anterior cast) dalam posisi full plantar fleksi maksimal selama 2 minggu. Setelah 2 minggu, jahitan dilepas dan plaster cast nya secara bertahap didorong hingga sampai dorsofleksi. Enam minggu setelah operasi, plaster cast dilepas dan dilakukan rehabilitasi. Pada kasus ini, setelah rehabilitasi, pasien dapat melakukan gerakan plantarfleksi maksimal dan mengangkat tumit pada satu tungkai yang telah dioperasi.

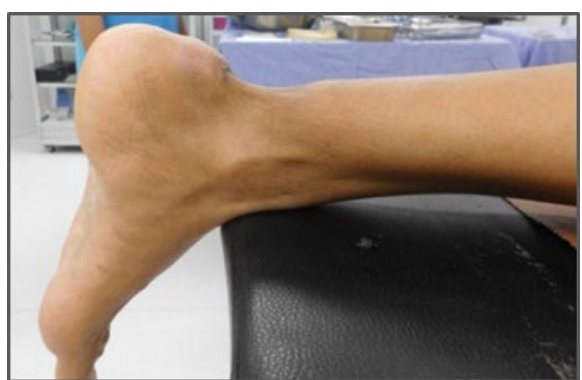

Gambar 2. Tampak gap di tendon Achilles yang rupture.

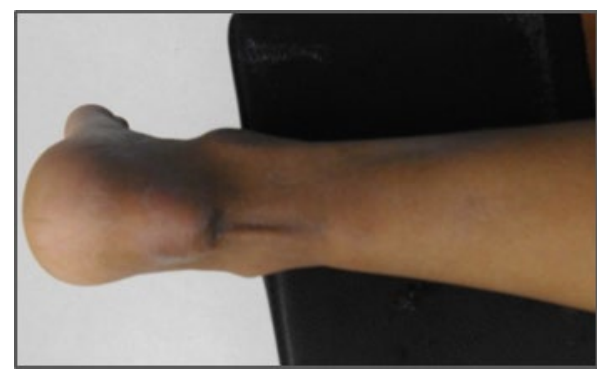

Gambar 3. Pasif plantarflexi masih tampak gap

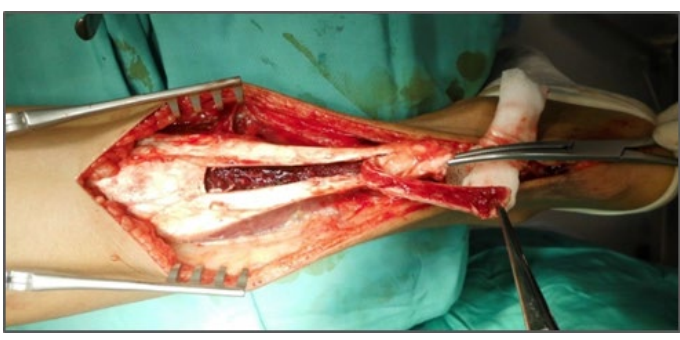

Gambar 4. diambil flap dari tendon dan aponeurosis m.gastrocnemeus, tendon plantaris di preservasi

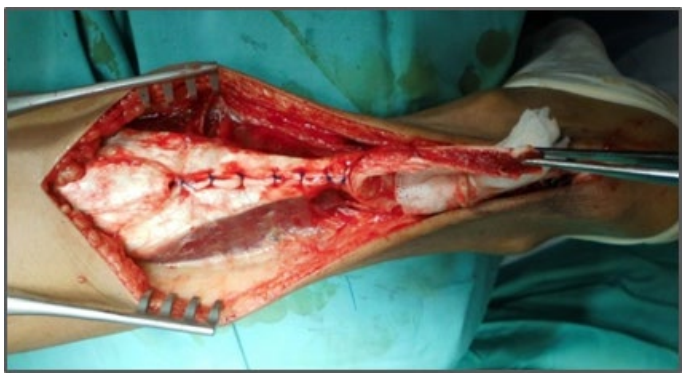

Gambar 5. tendon dan aponeurosis m.gastrocnemeus dijahitkan kembali

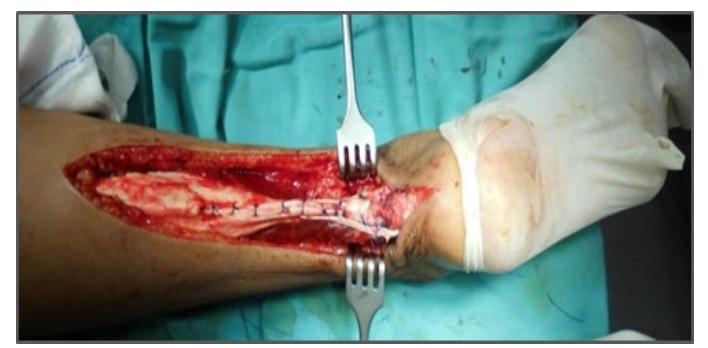

Gambar 6. Flap setelah dijahit dan menghubungkan stump proksimal dan distal, gap (-). Tendon plantaris sudah dijahit figure og eight 


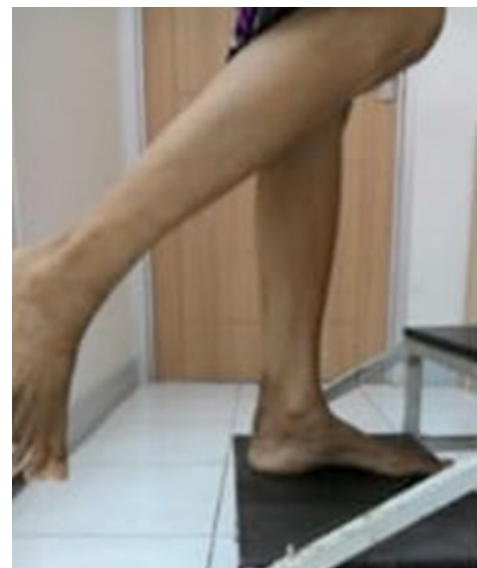

Gambar 7. Pasien dapat berdiri satu tungkai yang cidera

\section{DISKUSI}

Modifikasi yang dilakukan pada teknik Lindholm pada kasus ini adalah flap yang diambil hanya satu buah, hal ini karena ukuran donor tendon dan aponeurosis gastrocnemius pasien kecil, sehingga jika dipaksakan diambil dua flap, maka sisa donor akan tidak adekuat.

\section{SIMPULAN}

Tersedia banyak pilihan tatalaksana untuk rekonstruksi ruptur tendon achiles neglected. Tidak ada penelitian yang menunjukan bahwa salah satu teknik lebih baik dibandingkan teknik lainnya, oleh karenanya tidak ada gold standard penanganan kasus ini. Namun, rekonstruksi bedah diyakini menghasilkan outcome fungsi yang optimal. Terlepas dari teknik yang dipilih, tujuan akhir dari perawatan bedah adalah untuk memulihkan length tension relationship sehingga kekuatan gerakan plantarfleksi yang memadai dapat tercapai. Kemampuan pasien untuk berdiri dengan mengangkat tumit pada satu tungkai yang telah direkonstruksi mengindikasikan outcome yang sukses $^{1,2}$.

Pasien yang memiliki faktor risiko atau kapasitas fungsional yang rendah mungkin lebih baik ditatalaksana dengan brace karena komplikasi dari rekonstruksi bisa lebih buruk ${ }^{1,4}$.

\section{DAFTAR PUSTAKA}

1. Lee J, Schuberth JM. Surgical Treatment of the Neglected Achilles Tendon Rupture. Dalam: Cretnik A, editor. Achilles Tendon. Rijeka: InTech; 2012. 115-144. Available from: http://www.intechopen.com/books/achillestendon/surgical-treatment-of-neglected-achillestendon-rupture

2. Mafulli N, Ajis A. Current Concepts Review Management of Chronic Ruptures of the Achilles Tendon. J Bone Joint Surg Am. 2008; 90(6):134860

3. Park YS, Sung KS. Surgical Reconstruction of Chronic Achilles Tendon Ruptures Using Various Methods. Orthopedics. 2012; 35(2):e213-8.

4. Konecny J, Veverkova L, Reska M. Current Possibilities of Treatment of Achilles Tendon
Rupture. A Review. Scripta Medica. 2006; 79(2):75-84

5. Azar FM. Traumatic Disorders. Dalam: Canale ST, Beaty J. Campbell's Operative Orthopaedics. $12^{\text {th }}$ ed. Elsevier; 2012. 2311-24.

6. Park YS, Sungkas. Surgical Reconstruction of Chronic Achilles Tendon Rupture Using Various Methods. Orthopaedics, 2012; 35(2):213-6.

7. Toker S, Kilincoglu V, Yurtgun MF. Repairing an Achilles Tendon Rupture Using the Partial Lindholm Technique Augmented by the Plantaris Tendon. A Case Report. Eurasian J med. 2008; 40(3):148-50.

8. Pradeep J, Parthapratim D, Prabal G, Amol P, Shammi P, Vaibhav J. Management of Neglected Achilles Tendon Division: Assessment of Two Novel and Innovative Techniques. A Clinical Study. Advanced in Orthopaedic Surgery. 2014; 2014 